\title{
COMPUTER AIDED DISPATCH - A TOOL FOR EFFECT-BASED MULTINATIONAL AND INTERAGENCY OPERATIONS
}

\author{
Velizar SHALAMANOV
}

\begin{abstract}
This article presents a general model for effect-based multinational and interagency operations coordination by means of a Computer Aided Dispatch (CAD) tool. The focus is on the analysis of this model as integration based on CAD technology between incident, emergency, and crisis management C4ISR systems in order to be used in effect-based multinational/ interagency operations with heavy military forces participation. A CAD-based C4 model for incident/ emergency/ crisis management requires a lot of tests before industry/ field implementation owing to its complexity. This is the reason why the presented work considers the role of computer simulation experiments in driving this change, using the general process of Concept Development and Experimentation (CDE) used in NATO.
\end{abstract}

Keywords: Computer Aided Dispatch, Effect-Based Operations, Integrated Security Sector, Emergency Management, Crisis Management, Concept Development and Experimentation, CAX.

\section{Introduction: Effect-Based Multinational/ Interagency Operations and the Integrated Security Sector}

The context of effect-based multinational/ interagency operations is related to the increasing role of coordination and integration both at operational and system/ technical level on one hand, and at horizontal/ vertical level, on the other.

The idea of third generation ${ }^{1}$ of Security Sector Reform (SSR) for the development of an Integrated Security Sector ${ }^{2}$ is considered as a source of operational requirements for horizontal integration (see Figure 1) to the Computer Aided Dispatch (CAD) ${ }^{3}$ based system for Command and Control (C2) of Effect-Based Multinational/ Interagency Operations of crisis management type. ${ }^{4}$

The current structure (see Figure 1) of the security sector, which includes different institutions with monopoly over the use of force or information operations in support of 


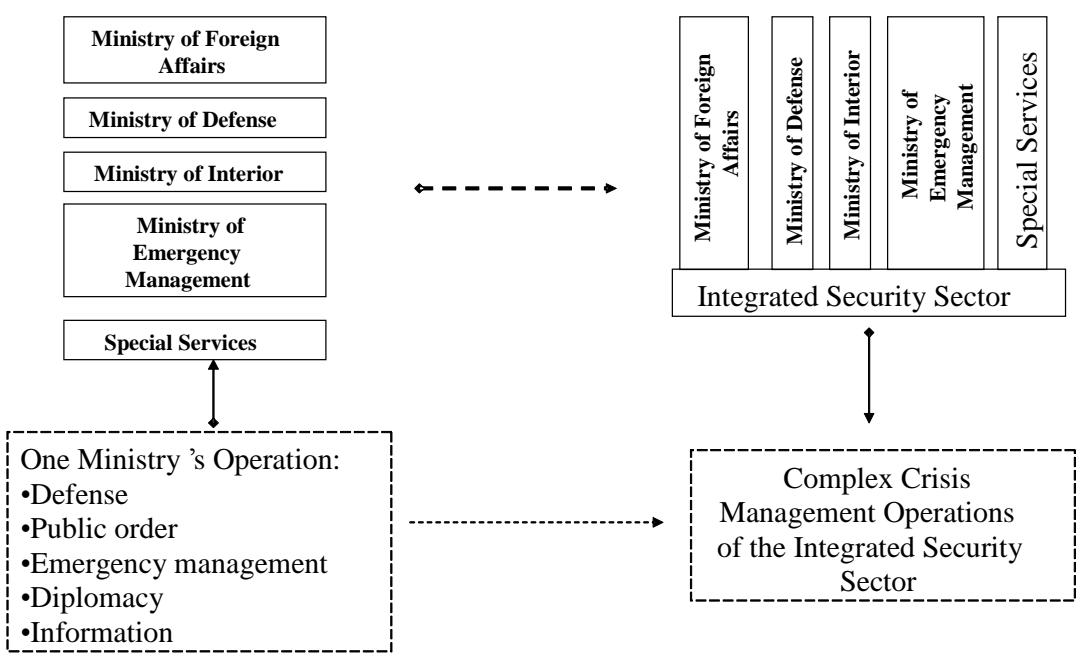

Figure 1: Third Generation Security Sector Reform (SSR) for Integrated Security Sector.

the use of force, mirrors the structure of well-defined and separate operations of use of force/ information support to the use of force. At the same time, nowadays, the security environment defines the need for complex incident/ emergency/ crisis management operations, where interagency, international, joint, private-public cooperation is essential. This reason drives the integration in the security sector, where different institutions keep their identity, together with the opportunity to form combined (international) joint (interagency) forces for specific complex operations with change of the mix of forces at different stage of an operation or when moving from one to another operation in the same region.

The integrated security sector is not an organization, but a concept for organization of the institutions participating in this network, in order to be able to work together, to support each other, and reinforce each other, while for a certain operation one institution has a lead according to the legal status of the operation.

The levels of Command Control Communications Computers Intelligence Surveillance and Reconnaissance (C4ISR) to be vertically integrated by CAD are shown in Figure 2.

In Civil Security, we have to consider C4ISR at least on five vertical levels and try to integrate elements of C4ISR on different levels in one system for seamless C2 of se- 
None Emergency Communications (for example “311”)

Emergency Communications (for example "911”, “112”, ..)

Emergency Management to include Integrated Emergency Management System (IEMS), Integrated Early Warning System (IEWS), Integrated Alert and Notification System (IANS)

Defense-Crisis Management / Expeditionary Operations to include National Military Command Center

Total Defense / Total War

Figure 2: Levels of C4ISR.

curity operations. This integration is not only a challenge for interoperability on technical and even operational level, but a serious issue on System Governance level. System Governance defines input and decisions that are made for the principles of building/ operating of the system, on the architecture of the C4ISR, development of infrastructure strategies, implementation of "business applications," and certainly on the investment in C4ISR systems/ components. ${ }^{5}$

Practically, on each level, there are interagency and even international dimensions to consider, but certainly going down from non-emergency response to the total war the requirements are getting higher and higher. Most of the time, it will be necessary to use non-emergency and emergency communications systems for providing the security and safety of citizens (in everyday life, these communications are closer to the citizens). The emergency, crisis management, and wartime systems are the most critical part and they will attract the majority of investment. This means that another governance challenge is to manage the resources in a way that will provide optimal level of functionality for all levels of the integrated system.

This article considers a general model for Effect-Based Multinational and Interagency Operations coordination by means of a Computer Aided Dispatch (CAD) tool as a solution on operational and technical level. It is based on the experience gained from operations for incident/ emergency management, performed by Police, Fire brigade, Medical emergency, and Civil Protection teams within the 911/112 emergency communications systems. ${ }^{6}$ The focus is on the analysis of this model as integration based on CAD technology between incident, emergency and crisis management C4ISR 
systems (or shorter, C4 systems) in order to be used in Effect-Based Multinational/ Interagency Operations with heavy military forces participation.

Effect-based operations are analyzed in the context of CAD for capabilities to:

- Identify point of incident/ required action;

- Identify type of required action;

- Identify teams available with the required capabilities for the required action;

- Direct, coordinate teams' actions;

- Assess the effect of the coordinated actions;

- Direct redeployment;

- Coordinate consequence management.

Certainly, when non-emergency calls are considered, the functions of CAD are mostly focused on informing the relevant service division of the municipality administration and on tracking the case until the request is answered (typically, reporting back to caller could take several days). When it comes to incident management, CAD focuses on the optimal reaction of the first responders, supposedly in seconds/ minutes. For emergency management, there are a lot of decisions to be made, such as:

- Optimization of evacuation;

- Optimization of deployment of rescue teams and critical resources (including water, food, medicines, protection devises);

- Optimal planning of consequence management activities for restoration;

- Input to mitigation planning, etc.

In the worst case of crisis management, there are even more critical decisions to be made and a common operational picture of what type of teams, where, are currently moving or operating, could be maintained by a CAD system (including Geographic Information Systems and Automated Vehicle Location), supported by wireless communications/ mobile data computers and record management systems.

For traditional military operations, CAD could be considered as element of maneuvering management to track forces. The Detect-to-Engage operational activity elements ${ }^{7}$ could be used for definition of requirements for CAD. These elements provide a methodology, linking warfare objectives with operational effects through the execution of specific processes. Utilizing this common set of processes to achieve operational effects ensures continuity with Commander's objectives across the joint forces and multinational environment. A detailed description of the Dynamic Targeting Cycle (DTC) Operational Activity is required as a base for CAD requirements, including the Find-Fix-Track-Target-Engage-Assess operational activity. DTC provides a Detect-To-Engage process methodology linking sensor-to-effect, required to 
achieve warfare objectives. Utilizing this common set of processes to achieve operational effects ensures continuity with the objectives between joint and coalition forces. The DTC process is inherently flexible and applicable across the spectrum of operations.

The Targeting Cycle consists of six phases ${ }^{8}$ :

- Commander's objectives, guidance, and intent;

- Target development, validation, nomination, and prioritization;

- Capabilities analysis;

- Commander's decision and force assignment;

- Mission planning;

- Force Execution and Combat Assessment.

There is a big difference between incident management, when targets are received from calls or early warning systems, and a military operation, where the commander develops a set of targets based on his/her objectives and intent. For that reason, all other phases - capabilities analysis, decision, mission planning/ execution, and combat assessment - are more complex, but in essence most of the information is again in the form of CAD together with the related databases for generation of an operational picture.

From incident management point of view, the Combat Search and Rescue (CSAR) operations are closest to the typical $911 / 112$ operations. CSAR is defined as "...a specific task performed by rescue forces to affect the recovery of distressed personnel during war or Military Operations Other Than War." ${ }^{9}$ CSAR operations could be relatively simple or extremely complex, and could be conducted in nearly any operation, involving hostile or potentially hostile forces. Mission cycle times can vary from a few minutes to several days depending on the quality of information, availability and positioning of response forces, and threats. A timely response is usually required to prevent capture and may additionally be necessary to protect isolated personnel from extreme environmental conditions or to provide medical treatment often necessary as result of the incident that isolated the individual (aircraft ejection for example).

Rapid notification and dissemination of a CSAR event is critical to facilitate recovery in a timely manner and to protect isolated personnel while awaiting extraction. Detailed battlespace situational awareness during all phases of the operation is essential and consists of locating isolated individuals, identifying threats to both isolated personnel and rescue forces, and selecting routes and landing zones. Accurately locating isolated personnel quickly is a top priority and necessary to minimize or eliminate search time in the objective area. 
Other specific military operations very close to incident and emergency management are Joint Military and Civilian missions. In the Bulgarian Armed Forces, ${ }^{10}$ the Joint Military and Civilian missions are defined as "operations of crisis of non-military character that are organized, aimed actions of the formations of the Bulgarian Armed Forces, seeking to prevent, master, and settle the crisis of a humanitarian character inand out- of the country's territory."

A CAD-based C4 model for incident/ emergency/ crisis management requires a lot of tests before industry/ field implementation owing to its complexity. This is the reason why the presented work considers the role of computer simulation experiments ${ }^{11}$ in driving this change, using the general process of Concept Development and Experimentation (CDE) used in NATO. ${ }^{12}$

\section{Integration between Incident, Emergency, and Crisis Management C4ISR Systems}

The concept of providing citizens' security is seen on at least three levels ${ }^{13}$ :

1. Through an Incident Management System that receives calls from the citizens or another source, and reacts with capabilities of first responders - Police, Fire teams, Civil Protection teams, Medical Emergency teams;

2. If there are too many calls or calls for series of incidents, as well as information from the Early Warning System (part of the Integrated Emergency Management System - IEMS), or information from the Crisis Management System for large emergency, IEMS is activated through the network of Emergency Operations Centers, deployment of the mobile Emergency Operations Center, and in addition to Police, Fire, Medical, and Civil Protection, other capabilities from emergency support function areas (transport, utilities, others) are activated. In certain cases, elements of the defense forces (defense-related support functions from engineers, Nuclear Biological Chemical (NBC) protection units, medical, transport, and even special forces) are activated in support of civil authorities. In this case, the Incident Management System is "subordinated" to a certain extent to the higher priority emergency management operation.

3. If there is any kind of intentional external threat or any kind of threat to Bulgarian citizens from outside the country, the crisis management system is activated, and the emergency management and incident management systems are "subordinated" to the highest priority crisis management operation.

CAD is critical for an Incident Management System, linked with a Geographic Information System and related Automated Vehicle Location databases (including access to Automatic Number Identification and Automatic Location Identification data- 


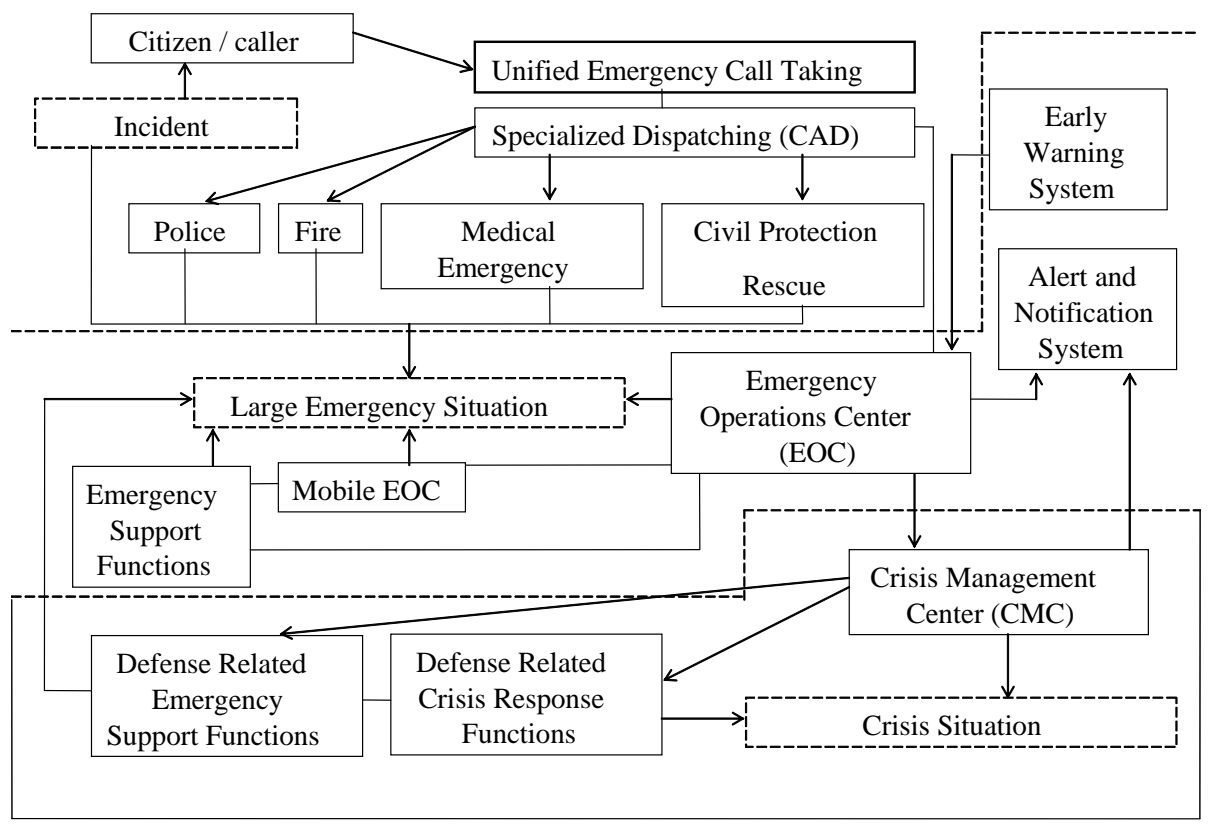

Figure 3: Integration between Incident, Emergency, and Crisis Management Systems.

bases), as well as sharing of this information between different centers - call taking, dispatch, operations.

On the level of the Emergency Operations Center, a new system for emergency management is required with capabilities to manage resources, messages, etc.; it has to be linked with the Early Warning System, the Alert and Notification System, the Decision Making Support System, and the enhanced Office Management System.

On the level of the Crisis Management Center as next level, a modern Command and Control system for intensive military involvement is required, but linked with the IEMS and Incident management system. The Crisis Management Center should have access to the Alert and Notification System and the Emergency Operation Centers.

In certain cases, especially on district and municipality level, the Emergency Operation Center and the Crisis Management Center could be one and the same facility, with certain specifics. There is a need for redundancy then, in order to have a main and an alternative center. When the city is a District/ Regional center, one of the centers (the main one) could be run by the Governor administration and the alternative center - by the Mayor administration, but with the idea to have two of them available both for the Governor and Mayor in order to save resources. 


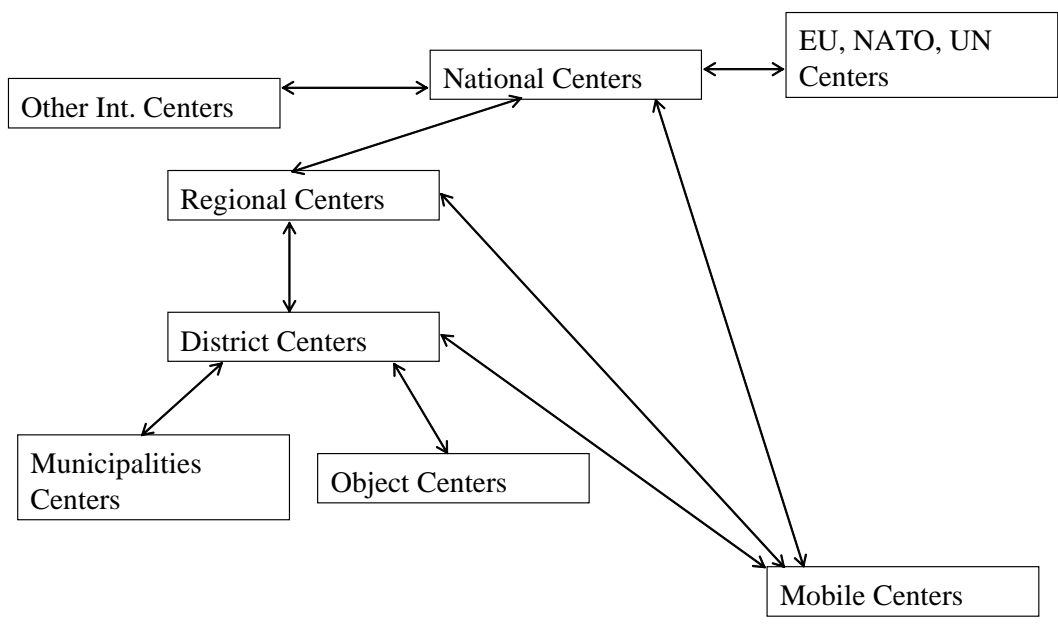

Figure 4: Network of Emergency/ Crisis Management Centers.

The architecture of the network of Emergency/ Crisis Management Centers (see Figure 4) has to be aligned with the administrative structure of the state and the legal base, defining the responsibilities. Other important relations in the system of incident, emergency, and crisis management, as well as defense/ public order and security arrangements in the state, have also to be considered.

As presented in Figure 5, there is a structure of call centers and respective dispatch centers to direct first responders. Obviously, this architecture has to be integrated with the emergency/ crisis management network architecture, with CAD as a main element responsible for sharing the same operational picture. On-site first responder coordination center is placed on a separate vehicle or it could use one of the first responder radio/ computer systems.

Based on the model presented in Figures 3, 4 and 5 for integrated incident/ emergency/ crisis management and its analysis, the Center for Operational Analysis (COA)/ Joint Training, Simulation and Analysis Center (JTSAC) focuses its studies and research and development efforts to define requirements for:

- Common operational picture used in CAD;

- Modeling and simulations tool to support planning/ training for such kind of operations;

- Decision support systems for incident/ emergency/ crisis management operations; 


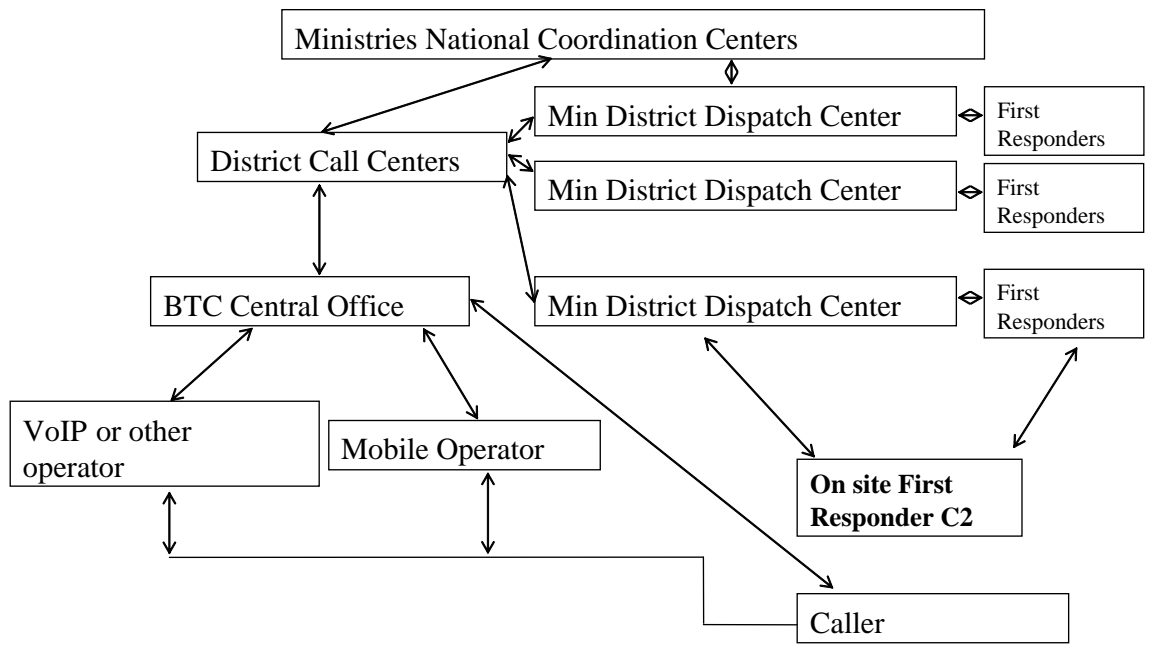

Figure 5: Network of Call/ Dispatch Centers.

- Network architecture required to control the operation;

- Planning, management, and assessment tool of the command and control system for such type of operations;

- Governance model for development of integrated C4ISR systems for effectbased operations;

- Financial model for development of integrated C4ISR systems for effectbased operations in countries with insufficient resources.

A common operational picture is defined as a set of actors with their behavior, possible scenarios, and environment of operation. The COA studies how to present this information in the databases and on the screen, as well as how to share the information about the common operational picture.

Modeling and simulations support for planning includes tools for scenario definition and simulation, ${ }^{14}$ decision-making support for responders' action in real situations, as well as for simulation of developments in the environment (including events, generated by opposing actors or nature, infrastructure, etc.).

The studied decision support systems focus on the support of CAD in optimal deployment of forces (teams) and resources, optimal search and rescue, optimal evacuation, etc. 
Network integration and management tools support the development of the technical architecture, its implementation, and real-time control.

The project/ operation planning, management, and assessment tool is used for preparation of the schedule for deployment and operation of the command and control system, its costing, budgeting, and assessment of the functional operation of the system.

The governance model studied considers the responsibilities and decision rights of all stakeholders in building and operating of the integrated C4ISR system for effectbased operations or the integrated incident/ emergency/ crisis management systems.

The financial model is directly related to the governance model and covers the issues of integrating all the available sources of funding through a trust fund, managed according to internationally recognized high standards for transparency, accountability, and effectiveness for achieving measurable certified results.

Requirements for these tools were developed in the framework of the NATO SfP981149 project and a prototype of the required network and software were tested during the Computer Assisted Exercise EU TACOM SEE-2006 in a test-bed called JTSAC-CS. $^{15}$

\section{Role of CAD in Integrated C4ISR for Effect-Based Operations: Concept Development and Experimentation}

When governance, architecture, infrastructure, operations, and even management aspects of the Integrated C4ISR for effect-based operations are considered, a need arises to apply the Concept Development and Experimentation (CDE) process, presented in Figure 6. The Joint Training, Simulation, and Analysis Center (JTSAC) that is used for support studies on this change management process is based on a specially developed model for concept development and experimentation in the area of civil security. This approach forms the basis for the change management process - transformation of the security sector into an integrated network-enabled organization, as goal of the third generation of security sector reform to address the challenges of defense against terrorism and other asymmetric threats.

JTSAC is an instrument, through which COA extends research, including modeling and simulation, in crisis management to support the exercises in this area. In particular, in the context of the exercise EU TACOM SEE-2006 (EU terrorist attack consequence management in a SEE exercise), COA supported:

- Strategic review of the civil protection system in Bulgaria and its EU/ NATO/ regional context;

- Development of Civil Security Concept for Bulgaria; 


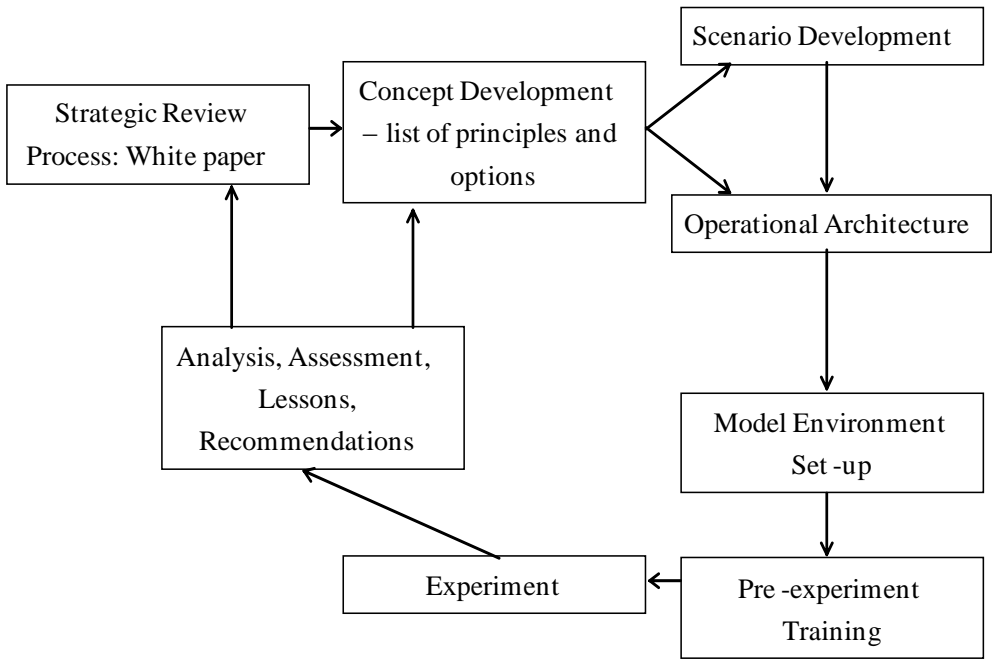

Figure 6: Experiment-Based Model for Concept Development and Experimentation.

- Development of General Scenario, Operational Architecture, and Message Flow;

- Establishment of a model environment based on JTSAC for implementation of the Operational Architecture and Message Flow;

- Individual and pre-exercise training of the participants in the exercise;

- Exercise implementation;

- Process of analysis, assessment, and lessons learned from the exercise;

- Update of the White paper on Civil Protection and the Concept for Civil Security.

Modeling and simulation plays a key role in the process of concept development and experimentation, since it provides integration of different organizations and technologies, as well as involves people in the loop of experimentation. In certain sense, the execution of the interactive experiment is a motivation and tool for joint work and well-documented results, providing objective data for analysis and adaptation of the concepts.

The simplified architecture of the EU TACOM SEE-2006 CAX, ${ }^{16}$ presented in Figure 7, aims to emphasize the scope and diversity of the involved Emergency Operations Centers (EOC) and the related Emergency Management/ Crisis Management systems - the Field Emergency Operations Center (FEOC), the District Emergency Operations Center (DEOC), the Ministerial EOC (MEOC), the National EOC (NEOC), and International EOC. 


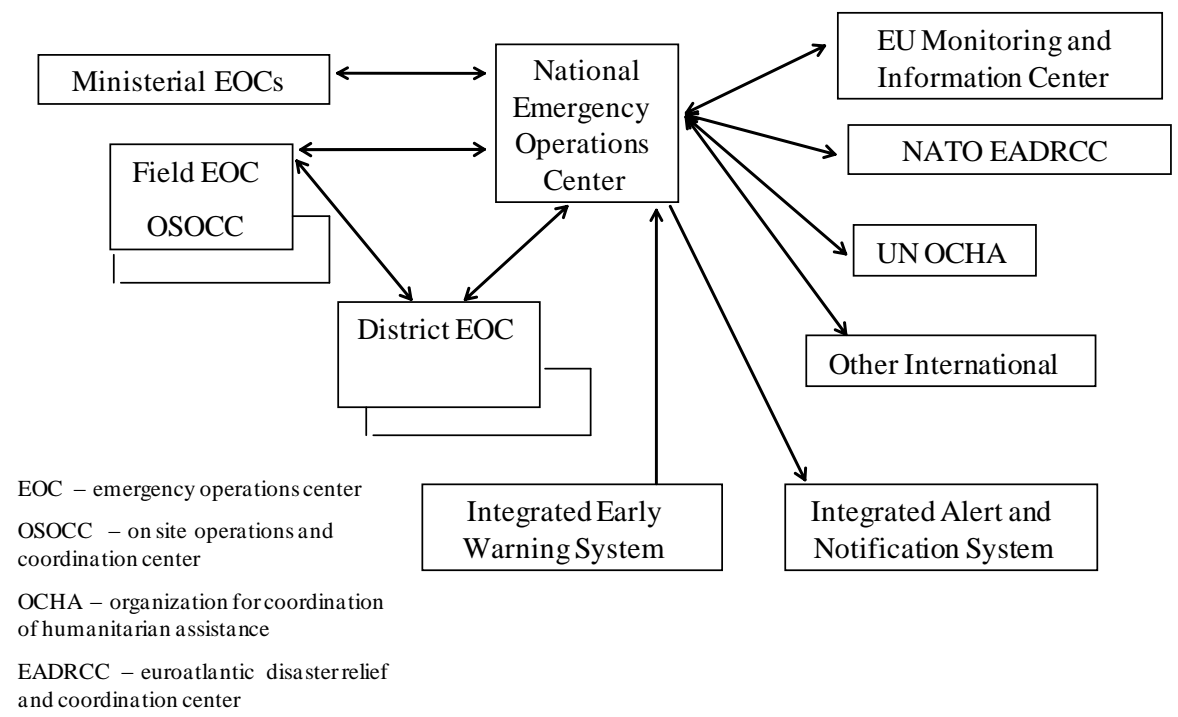

Figure 7: Configuration of CAX EU TACOM SEE-2006.

Such an exercise, focused on incident management, crisis management, or military effect-based operations with involvement of call and dispatch centers, first responders, etc., is of critical importance to verify the architecture and operational procedures developed for future use.

Figure 8 illustrates the environment for exercises/ research on C4ISR of the Integrated Security Sector. This hardware/ software/ models environment is under development in JTSAC, and is open for integration of elements, developed by different teams from the Bulgarian Academy of Sciences, ${ }^{17}$ other research centers, or companies, working in the field.

In this environment for concept development and experimentation, as in the real C4ISR systems for effect-based operations, the CAD for effect-based teams has a critical role to track every team and incident/ target. All other systems are contributing with data to the framework information in $\mathrm{CAD}$, generating the common operational picture in such a way.

Another key element of the environment is the federation network bus and low-cost commercial-off-the-shelf software and access to Internet. Owing to this fact, the envi- 
ronment is open enough to other software packages and focused on interagency/ multinational exercises.

\section{Conclusions: CAD as a Tool for Horizontal and Vertical Integration of Command and Control for Effect-Based Operations}

Experiments prove that the new technologies could support very effectively the vertical integration between incident, emergency, and crisis management operations under the concept of effect-based international and interagency operations of the integrated security sector (horizontal integration). In this horizontal integration effort, the key tool is the CAD system.

The efficient use of such a system requires special modeling and simulation tools for planning and real-time decision-making support. Other important aspects are planning, management, and assessment of the command and control system.

All this raises the issue of governance, architecture, operational procedures, training and program management of future command and control systems in support of effect-based multinational and interagency operations and emphasizes the role of re-

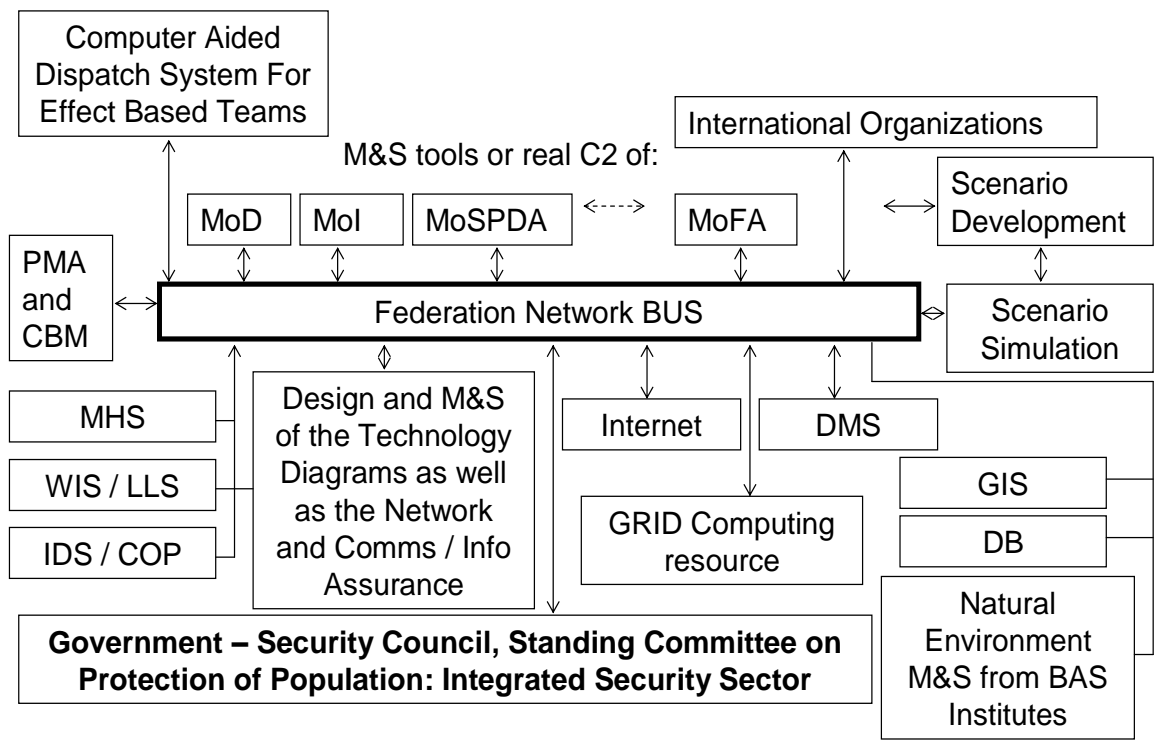

PMA - Planning, Management and Assessment; CBM - Continuity of Business Management; DMS - Decision Making Support; M\&S - Modeling and Simulation; DB - Data base; GIS - Geographic Information System; MHS - Message handling System, WIS - Web Information System, IDS Integrated Display System (COP), GRID - European R\&D network of computing resources,...

Figure 8: Hardware/ Software/ Models Environment for Experiments in Crisis Management. 
search, development, and experimentation to support these processes.

These challenges are addressed through a number of NATO/ EU sponsored projects with some national support to provide a start-up for COA/ JTSAC. Further development could require institutionalization of the process of concept development and experimentation of C4ISR for effect-based operations and integration of this effort into the NATO framework.

\section{Acknowledgement}

This publication is supported by NATO's Scientific Division in the framework of the Science for Peace Program - Project SFP-981149 (2005-2007) "CoE in Operational Analyses" (http://www.gcmarshall.bg/sfp981149/).

\section{Notes:}

${ }^{1}$ Philipp H. Fluri and Velizar Shalamanov, eds., Security Sector Reform - Does It Work? Problems of Civil-Military and Interagency Cooperation in the Security Sector (Geneva/Sofia: DCAF and GCMA, 2003), 240 .

2 Fluri and Shalamanov, Security Sector Reform - Does It Work?

${ }^{3} \mathrm{CAD}$ is used in incident management systems to dispatch first responders from Police, Fire service, Medical emergency service, or others. Such a type of system is in the kernel of the well-known in the US 911 Emergency Communications Systems and in the unified emergency telephone number 112, used in EU. Normally, CAD is linked with a Geographic Information System (GIS) and other databases.

${ }^{4}$ Velizar Shalamanov, "New Challenges for Crisis Management," in Crisis Management in the Republic of Macedonia (Skopje: MoD of Macedonia, 2005), 41-46.

5 Velizar Shalamanov, "C4ISR in Modernizing Security Sector in Bulgaria and South-Eastern Europe," Information \& Security: An International Journal 6 (2001): 7-22.

6 The 911/112 emergency communications systems are used to manage incidents by first responders after receiving calls from the citizens on a unified telephone number (in US 911, in EU - 112).

7 Joint Publication 3-60, Joint Doctrine for Targeting, 17 January 2002.

8 Joint Publication 3-60, Joint Doctrine for Targeting.

9 U.S. Joint Publication (JP) 3-50.21, Joint Tactics, Techniques, and Procedures for Combat Search and Rescue. 
10 “The Doctrine for Operations Different from War,” Chief of the General Staff’s order №296 (6 December 2000)

${ }^{11}$ Practically, this is organized in the Institute for Parallel Processing (IPP), Bulgarian Academy of Sciences), through a Center of Excellence in Operational Analysis (COA) and its Joint Training Simulation and Analysis Center (JTSAC), established under the framework of NATO SfP-981149 project and many other EU and nationally supported projects.

${ }^{12}$ Velizar Shalamanov, "Integration of $\mathrm{C} 2$ and M\&S Elements in CAX for Crisis Management," in Scientific Support for the Decision Making in the Security Sector, NATO Science for Peace and Security Series, Volume 12 (Amsterdam: IOS Press, 2007), 50-61.

${ }^{13}$ Jeffrey Winbourne and Velizar Shalamanov, "Emergency Management Pillar of the Civil Security: Practical Approach," Security Issues 3 (Tirana, Albania, 2007): 60-79.

${ }^{14}$ Zlatogor Minchev, "Intelligent Scenario Development for CAX," in Scientific Support for the Decision Making in the Security Sector, NATO Science for Peace and Security Series, Volume 12 (Amsterdam: IOS Press, 2007), 16-24.

${ }^{15}$ Scientific Project No.9 from the Working Program for 2005 of the Science Coordination Committee with the Standing Committee for the Protection of the Population against Natural Disasters, Emergencies and Catastrophes: "Analysis and Adaptation of Models from NATO Consultation, Command and Control Agency (NC3A) and European Community and NATO Countries for Analysis, Assessment, Decision-Making, Planning, Crisis Management and System Ensuring for Computer Assisted Exercises (CAX) on National and Regional Level (South-East Europe (SEE) and Black Sea Region Countries)."

${ }^{16}$ This was a high-visibility exercise with participation of six countries plus EU and NATO and observers from 17 countries. From Bulgarian side it was led by VPM Etem, Minister of Health Gaydarski, Minister of Environment and Waters Chakarov, and participation of MoI, $\mathrm{MoH}, \mathrm{MoD}$, MoFA, MoAF, State Agency "State Reserve," districts of Plovdiv and Vratsa, more than 10 institutes of the Bulgarian Academy of Sciences, two universities and about five small and medium enterprises.

${ }^{17}$ Most importantly, this test-bed is used for training of young scientists under NATO SfP 981149 and SfP 982063 projects and to develop national capacity in Operational Analysis and $M \& S$ support for force transformation in building integrated security sector with capabilities for effect-based operations.

VELIZAR SHALAMANOV is Senior Research Fellow and Head of the C4 section of the Institute for Parallel Processing of the Bulgarian Academy of Sciences. He is Chairman of "George C. Marshall"-Bulgaria. From November 1998 till July 2001 Dr. Shalamanov was Deputy Minister of Defense, responsible for defense policy and planning. He has more than 150 publications in the areas of CIS architecture and development, information warfare, decision support, national and regional security policy, defense planning and reengineering. Dr. Shalamanov is co-founder of the AFCEA-Sofia Chapter and the Business Executives for National Security - Bulgaria. He serves on the International Advisory Board of DCAF. E-mail: Shalamanov@GCMarshall.bg. 